\title{
The economics of changing course ${ }^{1}$ Implications of adaptability and inertia for optimal climate policy
}

\author{
Michael Grubb ${ }^{2}$
}

\author{
Thierry Chapuis and Minh Ha Duong 3
}

This paper reviews evidence that energy technologies and systems adapt over time to accommodate external pressures: that technical innovation and systemic change in the energy sector is largely induced by need, and restrained by potentially large transitional costs. A simple integrated model of optimal greenhouse gas abatement over time is presented, in which the abatement cost depends on both fixed and transitional elements. It is shown that the optimal current response and long-run prospects differ radically between the classical economic case - in which the cost of a given cutback in emissions is fixed exogenously - and the adaptive case - in which the response is ultimately adaptive but heavily constrained by inertia (ie low fixed but high transitional cost). If energy systems are indeed to a large degree adaptive, the results demonstrate that as compared with the classical non-adaptive case: long-run stabilization of atmospheric $\mathrm{CO}_{2}$ may be optimal even with moderate damages from climate change; greater near-term abatement efforts are justified; and the cost of a given delay in response may be several times higher. Neglect of the issue of induced technical change and other adaptive responses may invalidate the policy implications drawn from most integrated assessment models developed to date.

Keywords: Climate policy; Technological change; Adaptive responses

1 Preprint archived at http://halshs.ccsd.cnrs.fr/halshs-00002455. Final version published in Energy Policy, Vol. 23, No. 4/5, pp. 417-432, 1995, doi:10.1016/0301-4215(95)90167-6

2 Energy and Environmental Programme, Royal Institute of International Affairs, 10 St James's Square. London SWI Y 4LE, UK

3 Centre International de Recherche sur l'Environnement et le Développement (CIRED-CNRS), Campus du jardin tropical, 45 bis avenue de la belle Gabrielle, 94736 Nogent sur Marne CEDEX, France 
Innovation responds to need; and if properly nurtured, research and technology will respond to environmental and energy imperatives [Daniel Yergin, The Prize, 798]

Business is a large vessel; it will require great common effort and planning to overcome the inertia of the present destructive course, and to create a new momentum toward sustainable development [Schmidheiny et al, Changing Course, xxii]

This paper is ultimately about the capacity for change. Specifically, it is about the scope for energy technologies, systems and the societies that depend upon them to adapt to different conditions; the determinants of and limitations to the degree and rate of change; and the implications of this for policy towards limiting greenhouse gas emissions. But the underlying issues involved, and the possible implications for a range of other public policy questions, are much broader.

The enquiries which led to this work were stimulated by a variety of observations: the widely differing patterns of energy use in different countries; the radical degree and persistence of the changes wrought by the oil shocks of the 1970s; the variety of technologies and other responses that have been advanced for addressing the threat of climate change. Most of all it was stimulated by the debate about the costs of limiting $\mathrm{CO}_{2}$ emissions: the apparent immensity of the gulf between 'optimists' and the 'pessimists' in the abatement cost debate.

The 'optimists' in this context are those who argue that greenhouse gas emissions can be limited at little or no loss of welfare, irrespective of benefits from reduced climate change itself, and they range from the scientists and engineers that insist that technical fixes can make abatement painless to philosophers who insist that our whole lifestyles and value systems can and must change without loss of real welfare. The 'pessimists', in contrast, warn about the fantastic costs of stabilizing the atmosphere and query whether the benefits are in any way commensurate. This paper focuses most upon the debate about abatement costs, but the salience of the other observations will become apparent.

The paper is in three main parts. The first part explores the reasons for such widely differing views about abatement costs, and draws from this and other observations some more general insights into the nature of the abatement problem. The second part then presents a highly simplified model which aims to capture the essential dimensions of the argument, and presents basic results of how different perspectives affect the optimal response. The final part then extends the analysis to explain the observed behavior and the potential implications for abatement policy. 


\section{The issues}

\section{The abatement cost debate}

Consider for a moment what a complete newcomer to the debate about the costs and desirability of limiting greenhouse gas emissions would observe. In one corner are those whose analysis derives from the theoretical framework for analyzing aggregate human preferences, and responses, as mediated primarily by prices. They are concerned with developing public policy to maximize human welfare, according to utilitarian principles. Their discipline has proved so useful and powerful that modem societies are built around its precepts and use its indicators as primary measures of success. The discipline is called economics, and many who specialize in it - with important exceptions that we shall return to below - are concerned that extensive limitations on greenhouse gas emissions will adversely affect human welfare.

A second group of analysts focus instead upon analyzing alternative possible techniques for achieving specified ends: the techniques may be called, in the broad sense of the word, technologies, and these analysts derive mostly from the studies of the natural sciences and engineering. Whether they know it or not, in considering policy most are also guided by broadly utilitarian principles and those who have become involved in the climate debate are similarly concerned to maximize human welfare. But - again with exceptions most advocate wholly different conclusions from the economists: that we can and should take radical action to limit greenhouse gas emissions, because there is such a plethora of options available, or potentially available, for meeting human needs and wants without emitting greenhouse gases.

To confuse matters further, let us introduce a third disciplinary approach; call it behavioral philosophy, as a suitably ill-defined term which may stand for the combination of radical ecologists, sociologists and a range of others who adopt neither of the above perspectives. Some are concerned simply that we should stop fooling around with the planet, whatever the apparent welfare costs today. Some - often the same - believe that a return to simpler, humbler lifestyles would anyway lead to a better life. Most of this group believe that we can and should learn to become less obsessed with material consumption and the burning of carbon that goes with it, and that by putting more emphasis upon the quality of our physical and social environment we would anyway be better for it.

One of the peculiar features of the climate debate is that the latter two groups tend to advocate quite similar responses, though they start from wholly different premises; while the 'economists' and the 'technologists' - who share a common faith in empiricism, the scientific method and utilitarian-based rationality - are in bitter disagreement.

We shall argue in a moment that this is not really so peculiar, but let us return first to our observer. Some researchers may have been educationally or emotionally preprogramed to accept one or other of these paradigms; otherwise they may just be confused. If they are from government or business, they may wonder at the wisdom of spending money on public policy research. If they are from Mars, the response may be to go in search of a species that is somewhat better at cross-disciplinary communication. For surely, at least among the two groups which share such an extensive intellectual foundation, there must be some way of deciding clearly which is right and which is wrong that all can see?

A central argument in this paper is that the confusion arises in part because the question itself is misconceived. The division is not really so much about costs. It is about timescales. 
To see this, assume for a moment that the 'technologists' are right. A vast array of technologies and processes are possible that can provide the consumption we crave without burning carbon, at no additional resource cost (ie they do not intrinsically require any more input of capital, labor etc than more carbon-intensive alternatives). We can have superinsulated houses, cheap fluorescent lights, renewable electricity, and cars that are driven ultimately by-solar energy. Does it follow that we can slash carbon emissions tomorrow without cost? Of course not. Many of these technologies are not actually available as reliable, commercial products. Even if they were, the infrastructure required to supply many is not in place. Even if we were to install all those that are available and do not require such infrastructure, we would have to demolish huge amounts of existing capital stock before the end of its economically useful, polluting life. And even if we neglected that, slashing carbon emissions would slash the livelihood of all those whose jobs depend upon selling carbon and cannot at once develop skills for alternative work opportunities.

This is (or should be) common sense, and of course the more sophisticated engineering system models do include some of these elements. But they omit others. The phenomena are more intrinsically the stuff of economics: they reflect the behavioral and systemic realities of our current socioeconomic system, and the potential costs of imposing sudden deep constraints upon the complex and interwoven pattern of optimal resource use that markets have struggled towards.

Does this then mean that the economists are right, with their calculations of the GDP losses that carbon constraints may bring in the next century? Again, no especially not if we look far enough ahead. Even the most narrow-minded practitioner would admit that neither current markets nor technologies are perfect. If we were to force them to look a 100 years hence, and to compare the present with a 100 years ago, s/he would admit that humans have an extraordinary capacity for change and innovation (a point stressed in the climate context by Ausubel (in this issue)). Whether or not s/he believed the current designs of technologies, s/he would be foolish to insist that we will be forever incapable of finding ways of meeting our desires without emitting carbon.

The difference then arises, to a large extent, because the tools of the two disciplines are rooted in different timescales. Economic analysis is rooted in the technologies in use today, and the behavioral patterns and preferences revealed in today's markets; we shall argue in the next section that this applies even for those that claim to model the next 100 years. Conversely, even the most conservative of engineering studies, that focus upon proven and commercially available technologies, are to an extent dealing with an abstract time independent of today's market structures and infrastructure. And those that look forward to unproven technological possibilities refer - in comparison with the economic outlook to a timeless infinity, an optimal configuration bounded only by the limitations of our imagination. Economists, after all, are trained to look at what is and what has been, in terms of techniques and behavior; engineers are trained to look at what could be. It is not surprising after all that they arrive at totally different conclusions.

Nor is it surprising that the third paradigm noted above identifies more closely with the technologists, despite its sometimes active hostility to technology. After all, although the behaviorists and sociologists among them focus upon behavioral realities, they are too aware of the differences, between times and cultures, to accept economic analysis based on the assumption that these functions are unalterable. They too are concerned with alternatives - what could be - more than what is, today.

The question of timescales, then is fundamental to understanding the debate. But the alert reader will have noted that it has two important facets, not one. The first is what we may 
call adaptability - the ultimate capacity for change. The second is inertia - the pain of change. This paper explores these two dimensions in the context of energy systems, and the implications for the degree and timing of abatement.

Stated thus, readers with an interdisciplinary mind may be forgiven for thinking that this paper is about the obvious. But the fact is that economics has not really got to grips with issues of adaptability; and many engineering studies have avoided questions of socioeconomic inertia like the plague. Hardly any studies seem to have tried to characterize both elements and explore the implications for optimal climate policy. Which is what this paper, in a highly simplified way, attempts.

\section{Induced versus autonomous technical change}

The issue of adaptability may be cast in two different terms. One is the specific issue of technical development. The other is the much broader issue of human ability to adapt to different circumstances. The parallels with the second and third 'paradigms' noted above are obvious, but again they lead in similar directions. The important issue is how this differs from the paradigm embodied in most economic models, and for simplicity this section focuses upon the technical kind of adaptation.

Concerning climate change, a technologically optimistic outlook, such as that argued in the immense study of renewable energy technologies and applications edited by Johansson et al (1993) is that emissions could be reduced below current levels in the long-term with no long-term additional costs. It is argued that identified technologies can be proven and implemented at similar overall costs to fossil fuels. Whilst some authors suggest that economically viable technologies for extensive low-cost abatement are proven and abundant now, for supply substitution in particular most authors invoke the argument that costs will fall greatly if and as alternative technologies are developed and deployed on a largescale.

In terms of technology development, the important question is not whether technology develops, but why it develops in some directions more than others. Most long-run economic models applied to climate policy have been given assumptions that technologies will improve. But the key issue concerning technical change in this context is whether or not it is induced by external trends and pressures. This contrasts with autonomous technological change, which is projected to occur irrespective of other developments. Fundamentally, do we learn by doing, or learn from on high? (On high in this case may be equated with processes of $R \& D$ which proceed independently of the degree of other abatement efforts, discussed further below.)

The distinction is critically important. If technical change is induced, efforts to limit emissions help to stimulate technical and other developments, including economies of scale and learning, which in turn help to lower the costs of further abatement efforts. If technical change is autonomous, the costs associated with abatement are constant irrespective of policy, history of abatement efforts, and size of markets for lower carbon technologies.

In modeling terms, these may be termed endogenous (ie embodied within the model as a function of other factors) and exogenous (ie defined external to the model) technical change. Any model can be designed and run to encompass exogenous technical change, by lowering assumptions about the future costs of lower carbon technologies, and/or by using higher values for 'autonomous' efficiency improvements. Treating technical change as endogenous is much more difficult. And yet, there is overwhelming evidence that technical change is to an important degree -perhaps predominantly- induced by needs and pressures. 


\section{Evidence for induced technical change}

The process of innovation is not understood - given the high level of failure it has been characterized as 'the triumph of action over analysis' Various technology diffusion studies emphasize the complexity of factors which determine whether or not technological ideas are developed and adopted, and it is clear that this does depend heavily upon external conditions (Freeman, 1986). Grubb's study of 'Emerging energy technologies' which seem likely to have significant market impact over the next decade or two also concluded that 'most of technologies considered reflect primarily a process of "demand pull" rather than "supply push"' (Grubb and Walker, 1992).

Three specific examples, at successively greater levels of aggregation, illustrate the extent to which developments in technologies and energy systems are not autonomous, but reflect market and other external pressures.

First, when oil companies started operating in the deeper waters of the North Sea, it was on the basis of projections of oil prices rising to levels of US $\$ 50 / \mathrm{bbl}$ or more. In the early 1980s it was estimated that the cost of oil from new deep water platforms would be around US $\$ 25 / \mathrm{bbl}$. Yet as the oil price declined, companies responded with strenuous attempts to cut costs, leading to radical innovations in platform design and project management. Today, deep-water fields are still being developed by companies that believe that oil prices may not rise above US $\$ 20 / \mathrm{bbl}$ for many years, probably with production costs on the order of US $\$ 10 / \mathrm{bbl}$. Such developments required extensive efforts and commitment of investment in new techniques; they would not have occurred to anything like the same degree without the need to survive in response to declining oil prices. A similar story - but this time stimulated deliberately by massive market incentives in California - can be told of the development of wind energy.

A second example concerns the uptake of energy efficiency investments. In 1980, the UK Department of Energy carried out an assessment of the potential for energy efficiency improvements in UK industry. They concluded that industrial energy intensities could be reduced by about $20 \%$ over the following 20 years with cost-effective investments. In 1990, a new assessment concluded that most of the potential identified had in fact already been exploited; but that, despite the lower energy prices, almost a further $20 \%$ of cost-effective efficiency improvements could be identified. The greater interest and investment in energy efficient techniques in the UK and elsewhere - had apparently helped to generate greater development of more efficient techniques. Indeed, it seems a curious feature of energy efficiency studies that they seem regularly to identify cost-effective potentials for improvement of around 20-30\% of current demand, almost irrespective of the potential already exploited. There is a continual process of developing new options. It is hard to judge how much of this is driven by energy price changes and greater investment in energy efficient techniques, but the persistence of such results suggests that investing in greater energy efficiency helps itself to stimulate and identify options previously overlooked.

A third example concerns the macroeconomic response to the energy price shock and subsequent decline in energy prices. In real terms, energy prices in some sectors and countries are lower now than they were in 1972. Traditional econometric models based on constant price elasticities suggest that response to the price rise, marking a sharp decline in the trend of energy consumption especially outside the heavy industrial sector, should be mirrored by an equivalent rise after the price fall (after allowing for autonomous trends). In fact, although energy demand has started to rise again in most countries and sectors, the change has been nothing like as great as would be expected if there were indeed a 'symmetric' response. Energy economists have in the last five years begun to discuss the 
need for 'asymmetric' elasticities to model the observed behavior, with the decline in consumption in response to price rises being much greater than the equivalent rise in response to price falls ${ }^{4}$. One detailed econometric study (Walker and Wirl, 1993) observes:

Energy demand since 1986 seems inconsistent with the notion of constant income and price elasticities reported in the literature. Energy demand growth remained sluggish despite the simultaneous substantial reduction in real fuel costs and increases in real income.

Gately (1993) sought to quantify the price-irreversibility of world oil demand, and concluded that 'the response to price cuts in the 1980s is perhaps only one-fifth of that for price increases in the 1970s'.

Why is this? The argument is advanced that the price rises induced technology development, infrastructural investments and behavioral changes which were not 'unlearned' when the prices fell. Dargay (1993) presents his study of asymmetric responses as:

challenging two of the common assumptions made ... that a return to low energy prices ... would eventually restore demand to what it would have been had prices never risen ... not only does this not seem to be happening, but it also appears highly unrealistic. It is obvious that high energy prices induced the development and application of considerably more energy-efficient technologies in all sectors of the economy, many of which will remain economically optimal despite falling prices.

In other words - the essence of induced technology and systemic development, or adaptation to new conditions.

The Japanese experience with the aftermath of the oil shocks, outlined below, provides another clear and telling example.

At all three levels therefore - specific technology studies, sectoral assessments, and observed system-wide responses - there is overwhelming evidence that 'technology' development in the energy sector is not purely autonomous, but responds to external pressures $^{5}$. The data of the past 20 years are themselves leading energy economists increasingly to recognize a central role to the phenomena of endogenous technical change. The pity is that, with the partial exception of some studies discussed below, little of this insight is yet embodied in models of how we should respond to climate change.

\section{Broader adaptability}

The examples above all reflect observations in the energy sector over the past couple of decades. In the context of climate change - a problem which may span centuries - it is appropriate to note that the notion of adaptability can be set in a broader, deeper context, as well.

One illustration of this can be found in the substantial variations between different countries. It is striking, for example, that despite sharing a relatively open trading system

4 For example, J M Dargay, "Are price and income elasticities of demand constant? The UK experience', Oxford Institute for Energy Studies, Oxford, 1993, note 2, cites no less than nine studies which address the issue of irreversibility or asymmetry in energy demand - in addition to his own empirical studies which encompass France, Germany and the UK.

5 Note that this is not the same issue as that of 'embodied' lechnical change discussed, for example, in Bemdt et al (1993), which refers to the persistence of technological change as embodied in the unmalleable capital stock. 
and common technological base, Japan, Europe and the USA have such different energy systems and assumptions. Average energy consumption per capita in the USA is almost twice that in Japan and Europe, and national energy intensities differ substantially ${ }^{6}$. Japanese and European citizens do not in any way consider themselves seriously deprived by such lower energy consumption; it is perfectly normal for them. Yet cuts of 30-50\% in US energy consumption, or a shift towards Japanese or European gasoline pricing, would be regarded there with horror - for the simple reason that it would indeed represent a radical departure from the current situation. US infrastructure, technology and US citizens have adapted to a situation of energy abundance and low prices. The Old World, for reasons unconnected with global environmental concerns, has evolw $\sim \mathrm{d}$ and adapted in a slightly different direction.

Such observations would come as no surprise to psychologists or sociologists. Economics, too, when concerned with international comparisons, has long recognized that preference functions, and production functions, may vary between countries. It is an obvious corollary, and it follows from all the examples above, that they may also change over time. The 'classical' notion of fixed, or exogenously determined production functions, while useful as a short-term approximation within a specific country, is demonstrably wrong over longer periods. Technology, infrastructure and preferences are molded by history; they are to an important degree malleable - and hence adaptable.

Indeed, it can be argued that at root is an even deeper philosophical issue, harking right back in a mild form to the debates about determinism versus free will. The classical formulation - with exogenous technology and production functions - recognizes that we can change the future, but insists that it is only at an indefinitely recurring cost as compared with the 'optimal' path. An adaptivist perspective asserts that we can choose our future and - through our ingenuity and adaptability learn to love it.

\section{Inertia}

Lest this seem too easy, however, we need to return to the reasons noted above why the simplest technical optimism is seriously inadequate. The limitations noted above all boil down to the fact that socioeconomic systems are characterized by considerable inertia there is a cost to change. Psychologists have long noted that even apparently 'good' change, that people may actively seek, involves a certain amount of discomfort and stress. For other changes - including those that may be good at the macroeconomic level, such as overdue structural reforms - the personal cost for those that lose their jobs, perhaps to swell the ranks of long-term unemployed, is very obvious. At the systemic level too the costs of change are obvious, particularly for systems as long lived as energy systems. Investments in mines, power stations, oilfields and pipelines are often expected to earn returns over decades; buildings and transport infrastructure last even longer.

Thus the evidence for inertia in energy systems scarcely needs elaboration. Whatever the benefits, change is rarely costless, and the faster the change the greater the costs tend to be. At the most simple level, this reflects past investment in capital stock which may be rendered worthless; the OECD among others have pointed to the importance of including this effect with 'putty semi-putty' or other capital stock modeling (Hoeller et al, 1992). Rapid structural changes also generate macroeconomic disequilibria costs, as capital cannot be automatically switched from one sector or kind of investment to another. In social terms,

6 See for example Schipper and Meyers. 1993. These authors note that intensities can be misleading - for example because of structural differences - but such differences themselves rettect partly processes of adaptation to different conditions. 
sensitivity to the rate of change may be still higher, eg if it forces job losses much faster than feasible under natural turnover or even voluntary redundancy schemes. Rapid action may thus be much more expensive than action at a similar absolute level, phased over a longer period.

The issues of inertia and induced technical change are distinct, but related. Technology studies such as those collected in Griibler (1991, p 10), have emphasized the way in which technologies tend to generate 'clusters' of interlocking systems. Hourcade points out the implication that gradual change, developing a new and self-reinforcing trajectory of interrelated technical change, may be relatively cheap and self-sustaining, with little cost difference from an alternate 'businessas-usual' trajectory which leads ultimately to a wholly different pattern of emissions and technologies (Hourcade, 1993). Rapid change, however, may require large-scale adoption of technologies not well suited to current systems, incurring high transitional costs which decline only as the relevant supporting systems develop. Thus inertia and adaptability are the Siamese twins that disciplinary divisions have largely rent asunder - at great cost to our ability to develop a coherent understanding and analysis of how to respond to climate change.

\section{Endogenous technology and $R \& D$ in the economics literature}

Before going further, it is essential to add an important clarification, lest this paper begin to sound merely like an addition to the increasingly popular pastime of economics bashing. In the interests of simplicity we have focused upon one pole of the above dichotomy as 'classical' economics, the other as 'adaptivist'. It is important to note that innovation has featured as an important theme in economics since Schumpeter or before, and there is a growing strand of literature addressing questions of endogenous technical change. To date, however, it has not focused upon the issues, or taken the form, that we consider central to the question of timing climate change abatement responses and want to address here.

A growing number of formal energy and economic models do contain some elements of endogenous technical change. Examples range from specific energyclimate models to more theoretical environment-growth models. Among the former, the Manne-Richels Global 2100 model, by combining constraints on the rate at which technologies can penetrate the system with exogenous assumptions that technology costs do decline after a certain date, has a quasi-endogenous effect in which it may pay to invest in low-carbon technologies before they are economic so as to be able to exploit them more rapidly when the price falls ${ }^{7}$. Furthermore, by examining different cost assumptions, part of their original message though this element was not widely emphasized - was to highlight the extent to which technology development could lower long-run abatement costs, as a result of which they called for much greater R\&D efforts. Edmonds et al have applied their model to an even more dramatic illustration of the extent to which plausible assumptions about technology development can lower abatement costs (Edmonds et al, 1993).

Technology development is of course in many ways knowledge, and some economic studies have formally addressed it as such. Bovenberg and Smulders (1994), among others, have developed a growth model with a separately defined 'knowledge sector': investing in this lowers the costs of environmental constraints, and environment in turn features as an explicit input into the productive sector. They show that greater investment in the knowledge sector - which can be stimulated by environmental constraints - changes the time profile of growth but can increase rather than diminish long-run wealth.

7 Thus, the maximum allowable market size is influenced endogenously, though unit technology costs are not. 
These examples raise an important question about the mechanisms of innovation and adaptation. The call by Manne and Richels, Edmonds and others for more R\&D reflects a widespread belief that this is main mechanism involved. Implicit in the previous discussion of adaptation however is the view that systemic adaptation is about a much broader response. Indeed even on its own terms, public R\&D does not have a good record for directing effective technology development ${ }^{8}$. It tends to suffer from weak corrective feedback mechanisms, and it represents a rather small fraction of total knowledge-creating investment ${ }^{9}$. Systemic adaptation is as much about harnessing the direction of corporate interest and investment, and changing habits and expectations, as it is about formal R\&D though $\mathrm{R} \& \mathrm{D}$, dissemination and market stimulation undoubtedly have important roles to play $^{10}$.

A practical example is afforded by the Japanese experience since 1973. In an extensive study of the factors that have contributed to the exceptional pace of technological development in Japan, Watanabe et al (1991) note that Japanese R\&D investment rose steadily until by 1987 Japan ranked alongside Germany as having the highest R\&D intensity in the OECD, but that the government's share in total $R \& D$ expenditure was the lowest among the advanced countries. In parallel, they estimate that the stock of technical knowledge increased by a factor of seven from 1970 to 1987 . They trace the impetus for this investment, and the very high leverage of the government industrial $\mathrm{R} \& \mathrm{D}$, unambiguously back to the oil shocks (Watanabe et al, p ix):

The natural environment, especially energy problems resulting from external technology [sic:], was the inducing power of Japanese technological innovation from the mid 1970s to the early 1980s. R\&D directivity to energy stimulated the increase in $R \& D$ intensity as a whole. The trends in $R \& D$ directivity to energy coincided with the trends in the international oil prices.

A number of other authors have explored these broader notions of endogenous technical change. Carraro and Siniscalco (1993; see also Carraro et al, 1994) show that if a core group of 'advanced' countries take the lead in limiting emissions and thereby stimulate technical developments, they may be able to use this to entice other countries to join them, in an expanding coalition of countries, thereby overcoming the free-rider problem of countries seeking economic benefit by relying on others to limit emissions.

The role of technology diffusion is also addressed explicitly by Hourcade (1993), who models the impact of abatement policies as accelerating the diffusion of low-carbon technologies, again a process which does not necessarily reduce economic growth. Perhaps

8 Grubb and Walker (1992) studied emerging energy technologies, and concluded that 'there appears to be no discernable relationship between the allocation of government energy $R \& D$ expenditure over the past fifteen years and the technologies that now appear most likely to have a significant impact' (p 240).

9 For example, the World Energy Council (1992) estimate that capital investment alone in renewable energy commensurate with their 'ecologically driven' scenario would entail about US\$1.5 trillion additional investment, as compared with the reference case, over the 25 years to 2020 . This is equivalent to about 2500 years expenditure of the total R\&D budget for renewable energy by all IEA governments at the rates prevalent in the early 1990s (IEA, 1993, indicates this to be in the range U S \$ $5 \sim 00$ million in 1990-91; more recent data are not available). Thus public R\&D would have to be one hundred times as efficient at creating useful knowledge as private capital investment for the two mechanisms to be of equal importance in aggregate on this crude measure.

10 The observation about the dominant mechanism of total R\&D does not represent an argument against publicly funded R\&D and other measures, which can be profitably directed at areas where private investment is inadequate for a host of well-documented reasons. Public subsidies for procurement of private goods - for example with dissemination and market stimulation programs -- forms an interim bridge which can be particularly effective at stimulating productive RD\&D. 
the most explicit attempt to model endogenous technical change, in a way which provides some direct economic reflection of technologists' perspectives, is that by Anderson and Bird (1992), who model the unit costs of renewable energy technologies explicitly as a function of market size, using empirical data on the cost-volume relationship in other areas of manufacturing industry, and demonstrate that this greatly reduces the long-run costs of deep emission cuts.

These are important results which provide a refreshing optimism compared with earlier economic modeling forays into the issue of climate change. But there are three limitations which the rest of this paper seeks to address. The first is that many of these analyses are sufficiently complex to make it difficult for non-specialists to understand what is going on, and to grasp the important underlying issues. The second is that it is difficult to connect such analysis to more conventional economic studies to see how and why results are affected by the issue of endogenous change, rather than the many other inevitable differences between models. Third, none of these studies explore explicitly the implications of adaptability and inertia for the 'apex question' of how much effort should be made to limit emissions, and when (Grubb, 1993).

\section{The model and basic results}

This section summarizes a highly aggregated, topdown model which aims to illuminate the issues of adaptability and inertia in a way that addresses these three points. It reflects many of the limitations of such highly aggregated top-down models. It treats the world as one aggregated region; it has a highly simplified representation of the accumulation of carbon emissions in the atmosphere; it uses aggregate cost functions to represent complex abatement costs; and it has a simplified representation of the costs of climate impacts, in which costs are taken as proportional to concentration changes from pre-industrial times. These limitations some of which are shared by various other integrated assessment models in different combinations - however, do not undermine its applicability to the specific questions addressed here, namely that of examining how systemic adaptation and inertia affect the form and timing of abatement as compared with the 'classical' case.

\section{Structure of the model}

The first stage is based directly upon the problem as framed by Nordhaus (1991). The analysis concentrates upon $\mathrm{CO}_{2}$ emissions (although it can be applied to other gases), as the major long-term contributor to radiative change and the central source of concern about the impact and timing of any constraints. Equations are developed that link emissions with concentration changes in the atmosphere and hence ultimately to climate impacts ${ }^{11}$. The

11 The cost of climate change is taken as directly proportional to the change in atmospheric CO 2 concentration above pre-industrial levels. The real dependence is of course speculation, and other integrated assessment models embody various assumptions, including potential much more severe ones in which the impact costs increase linearly with the temperature rise. Since the focus in this model is upon the impact of changing assumptions about the dynamics of abatement processes, the choice of even a radically different static representation of impact costs is unlikely to change the qualitative conclusions. A more significant objection is that the process of coping with climate change is itself likely to involve innovation and other adaptative responses (the word adaptation has indeed been captured to refer to this aspect) to climate change. The situation is not entirely symmetric, because emissions anywhere near current levels still imply a constantly changing atmosphere, so that even complete adaptability on both sides of the equation should lead to long-run abatement to halt the change, but how it would affect the overall optimal strategy is unclear. Modeling genuinely adaptive responses to impacts was beyond the scope of this model (because it involves an additional degree of integration), hut it is an important 
simplest forms used in Nordhaus are adopted; more sophisticated models of the linkages can be brought to bear, but such refinement is not important in this context ${ }^{12}$.

The objective is taken to be to minimize the present (discounted) value of fractional loss of GDP, discounted according to a social rate of time preference ${ }^{13}$. In other words, the aim, as in all such optimizing models, is to find the emissions path which gives the optimum tradeoff between the costs of abatement and the cost of climate change impacts. The basic model is presented in Grubb et al (1994) and the main equations are set out in the appendix; only those central to understanding the representation of adaptation and inertia are set out here. Chapuis et al (1995) present further details and develop an equivalent numerical model that verifies and extends the analysis model summarized here.

\section{Emissions control}

Abatement is represented by an emissions control parameter $e(t)$ which determines the degree to which actual emissions at time $t, E(t)$, deviate from a reference path $\operatorname{Er}(t)$ in which there are no abatement efforts:

$$
E(t)=\operatorname{Er}(t) \times(1-e(t))
$$

Limiting emissions $(e(t)>0)$ incurs a cost; the reference $\operatorname{Er}(t)$ is by construction the optimal path of emissions in the absence of any abatement effort - this is not a model in which there are 'free lunches' arising from cost-effective but unexploited opportunities to improve energy efficiency or new supply options (this is an important debate, but not one central to the issues addressed here).

Since the central purpose of this analysis is to examine how inertia and adaptability may affect optimal abatement strategies, the abatement cost function takes a form which depends explicitly on both the degree and the rate of abatement, with quadratic dependence:

Abatement cost at time $t=C a \times(\text { degree of abatement } e(t))^{2}+C b \times($ rate of abatement $\left.e^{\prime}(t)\right)^{2}$

where $e^{\prime}(t)$ is the first derivative (ie the rate of change of abatement level). This simple form for the cost function is in fact the heart of the new issues captured in the model. The first term is equivalent to the abatement cost function in 'classical' aggregated cost-benefit studies such as DICE Nordhaus (1994). It represents the continuing cost of holding emissions at a level lower than the "reference' case. A more adaptive abatement response eg arising from endogenous technical developments that lowers the cost of low-carbon technologies over time is thus represented by a lower value for $C a$. The second term reflects inertia, in the most direct and simple way possible, in which costs depend on the rate of abatement.

Thus. choosing a lower $C a$ relative to $C b$ indicates that the long-run costs of abatement are lowered by induced technological development; the system starts adapting to abatement. If

research task.

12 Like the original Nordhaus analysis, it is a partial equilibrium model, with climate impact and abatement costs represented as a deviation from a baseline 'non-problem' reference economic growth rate. One reviewer considered the lack of full general equilibrium feedbacks a critical weakness in the model, but no one else has raised this concern and Nordhaus disputed the reviewer's contention that it was significant (personal communications). We do not see how general equilibrium feedbacks could significantly alter the conclusion from the model here.

13 For a classical logarithmic utility function, this is roughly equivalent to maximizing total discounted utility. 
$C a$ declines as $C b$, rises, abatement costs are increasingly dominated by the inertia of moving from one state to another, relative to the recurring costs of staying at any given abatement level. The optimal response is determined by the tension between the rising transitional costs of overcoming inertia and the declining absolute costs associated with abatement adaptation, set against the long-run benefits associated with reduced atmospheric change.

\section{Numerical assumptions}

For illustrative purposes, results are presented for the following basic values:

- rate of time preference $=3 \%$ pa

- carbon sink rate $s=3.7 \%$ pa

- pre-industrial $\mathrm{CO}_{2}$ level $m=550 \mathrm{Gt} \mathrm{C}$

- damage from doubling $\mathrm{CO}_{2}$ concentrations $\mathrm{Ci}=4 \% \mathrm{GWP}$

- initial emissions $E_{0}=7.5 \mathrm{Gt} \mathrm{C}$ pa

- emissions growth without abatement $=2 \%$ pa

These values are fairly central in the literature. The most contentious is the assumed costs of climate change impacts arising from doubling atmospheric concentrations; the value here is close to the average value in an expert survey by Nordhaus (1994) (this does not necessarily mean it is right, since fundamental uncertainties and issues of risk aversion remain: but the absolute value is of little relevance to the issues explored here).

The central purpose of the present paper, other than introducing the issues and the model, is to examine how the optimal trajectory varies as the costs of abatement are increasingly dominated by the tension between the inertia and adaptation to abatement, as represented in the above equation. An immediate issue arises as to how to make the trade-off between the declining 'absolute' costs, determined by $\mathrm{Ca}$, against the rising transitional costs associated with the rate of change, determined by $C b$

The approach taken is to fix the total abatement costs associated with a linear abatement schedule over a fixed period, and vary $C a$ and $C b$ so as to preserve this total cost. Given the longevity of the energy sector, and human habits, the period is taken as about a generation 30 years. Specifically, the cost coefficients are determined by assuming that the total costs of limiting emissions linearly to a final point of $50 \%$ below baseline projections over the period are constant:

$$
\int_{[0, T]}\left[C a e(t)^{2}+C b e^{\prime}(t)^{2}\right] \mathrm{dt}=\text { Constant }
$$

where for this analysis, $T$ is taken as 30 years and the constant - the total economic loss summed over the 30 year period - is taken as $20 \%$ of the final year's gross world product. This implies abatement costs at a level roughly equivalent to a purely fixed (exogenous) abatement cost function, in which the cost incurred from a $50 \%$ emissions reduction is $2 \%$ of GDP pa.

This parameterization defines the trade-off between $C a$ and $C b$,. A high $C b$, in this context reflects a view which still accepts the results from the major global topdown energy models as valid over the next few decades, but interprets most of these costs as transitional, and sees abatement costs beyond this being brought down steadily by the endogenous process of systemic adaptation to emission constraints. We examine three cases: 
- case 1: non-adaptive, low inertia, in which $C a$ and $C b$, are set such that $99 \%$ of the costs in Equation (I) are associated with $\mathrm{Ca}$ - the conventional perspective:

- case 2: half and half, in which the costs in Equation (1) are divided equally between the two terms:

- case 3: adaptive, high inertia, in which $99 \%$ of the costs in Equation (1) are associated with $\mathrm{Cb}$

\section{General results}

The results for these central values are shown in Figure 1 (figures are at the end of the paper). For the classical, non-adaptive/low inertia case, abatement jumps to an optimal level of about $6 \%$ emissions reduction, and then increases very slowly owing to the rising baseline emissions; this is basically the Nordhaus result, in form as well as order of magnitude ${ }^{14}$.

For the half-and-half case, when the abatement costs in the parameterization equation (1) are divided equally between transitional and absolute costs, abatement initially rises much more slowly. After about 11 years however it exceeds the 'ceiling' level of the classical case, and carries on rising to nearly twice that level.

In the adaptive/high inertia case, abatement rises to exceed the steady state level of case 1 after about 6 years, and it carries on rising at a rate which does not slacken in the period examined (in fact it accelerates fractionally owing to the rising baseline).

The absolute impact on total emissions is shown in Figure lb. In the classical non-adaptive case global emissions carry on rising (after the initial depression), shadowing the baseline increase. In the half and half case, the trajectories gradually diverge, though not enough to stabilize global emissions. For the adaptive, high inertia case, however, emissions progressively diverge; after 35 years global emissions have returned to the starting value, and are on a sharply declining trend towards stabilization of atmospheric concentrations.

It is emphasized again that this result is an optimal path for the parameter values and functional forms chosen. To an important degree the equations involved are simplistic and the numbers subjective - as in most such modeling exercises. But this does not invalidate the nature of the conclusions, nor are the numbers extreme. It is not a result driven by assumptions of very high climatic damage or fixed climate thresholds, or a very low rate of time preference; nor does it reflect particularly low estimates of the cost of abatement technologies as currently perceived. It is a result driven by the consequences of endogenous technical change in which the act of limit emissions in the first decade lowers the cost of abatement in the next, in a recurring process of technological and behavioral adaptation to the requirements of abatement.

The absolute values of course depend upon the assumptions used. Many of the key sensitivities are readily apparent from the form of the mathematical result (see the appendix). Thus, the optimal degree of abatement at all points is proportional to the assumed costs of climate impacts: doubling the climate damage function doubles the optimal degree of abatement. Similarly, for a constant ratio $\mathrm{Ca} / \mathrm{Cb}$, the optimal abatement is inversely proportional to the cost of abatement.

As the rate of time preference is lowered, placing more weight upon future impacts, the

14 In fact, Nordhaus uses a significantly lower estimate of climate damages, but a cubic cost function for abatement costs; his results reflect a trade-off at lower assumed impact and abatement costs, at such modest abatement levels, but his costs for much more extensive abatement rise very rapidly. 
optimal degree of abatement clearly rises, but the relationship is complex. Figures 2 and 3 show results corresponding to those above for rate of time preferences of $4 \%$ pa and $2 \%$ pa. In the former case, even for the fully adaptive/high inertia (endogenous technology development) case, global emissions are barely stabilized at the end of four decades given the other values used. In the latter case - comparable with the value promoted by Cline (1992) -emissions decline so rapidly that atmospheric concentrations would probably be stabilized after three or four decades.

\section{Analysis and implications of results}

\section{Long-run prospects}

The first conclusion of this study then is a message of relative optimism. If the process of abatement is in fact adaptive to the extent modeled in case 3 above, there may be solutions to the problem of climate change, with optimal responses stabilizing the atmosphere over a period of some decades at very moderate cost. This possibility is of course in sharp contradiction to the conclusions of most previous cost/benefit modeling studies which have argued that the costs of stabilizing even emissions, let alone concentrations, would be high and continually increasing.

This is not a surprising conclusion when the basic hypothesis of endogenous technological change and other adaptive processes in the form modeled here is understood.

\section{Initial rate of abatement}

Rather less intuitive is the rate of response in the first decade. It might be supposed that the rate of initial responses would be progressively depressed as the weight accorded to inertial/transitional costs increases. The results in Figure 1 illustrate that this is not the case beyond a certain point; for the adaptive/high inertia case (case 3 ) the abatement response is more rapid than in the half and half case.

The reason for this lies in the long-run impact on technological trajectories. Initial abatement stimulates technology and infrastructure development, and behavioral changes, which lower the cost of further abatement. As long as there is a substantial component of 'absolute' abatement costs - fixed and not susceptible to endogenous cost reduction - the benefit of any endogenous cost reduction is capped after a couple of decades by the absolute component of abatement costs. But if response is highly adaptive - eg abatement drives extensive technology development - the benefits are greater not only in terms of faster embodied cost reduction, but they also extend much further - the initial moves carry through to a pattern of more extensive abatement spanning over decades. The cost of early action rises, but the benefits rise faster; and thus, it is optimal to act faster to maximize the benefits of induced technological development and other adaptative responses which ease the cost of future abatement.

This interpretation is supported by the sensitivity studies with the discount rate. For the adaptive/high inertia case, the rate of abatement rises disproportionately faster for the lower rate of time preference, reflecting the high value attached to the long- term benefits of starting early upon a 'self-sustaining' abatement trajectory. 


\section{The cost of delay}

The cost of delaying abatement measures under differing assumptions about adaptability and inertia can be examined directly with the model, and again an analytic solution is possible (Chapuis et al, 1995). Applied to this question, the model shows that the cost of delay initially rises linearly with the delay time, as might be expected (Figure 4). After a few decades the cost of delay starts to level out and it is almost flat after 150 years (because by then the atmosphere is almost in equilibrium at much higher emissions rates and concentration).

For the $3 \%$ rate of time preference and the other central values listed above, the cost of a few years' delay in responding in the adaptive/high inertia case is about seven times the cost of delay in the classical, non-adaptive case; and even in the half and half case, where longrun abatement is still greatly constrained by the constant (non-adaptive) part of the cost function, the cost of delay is about $70 \%$ higher than in the classical case.

An important extension of the analysis would be to model optimal strategies under high uncertainty. It is in this respect that the element of inertia would become of particular importance, constraining the rate at which one could alter trajectories to adapt to new information about the severity of the problem. Arguably, this might be expected to amplify further the cost of delay as compared with use of a 'mean' damage estimate (perhaps depending on the rate of learning and distribution of outcomes), but this remains to be explored. Insufficient representation of inertia is, in the author's view, one of the major constraints of current integrated modeling assessments of decision making under uncertainty, and the model outlined here is currently being extended to examine explicitly this issue.

\section{Conclusions}

The paper has not sought to examine in depth the process of responsive or induced technology development implicit in the notion of 'adaptability'; it is a complex and poorly understood issue. The paper has however advanced observational evidence to suggest that technical, infrastructural and other change in the energy sector has to an important extent been of this character.

The real degree of adaptability and the best way to characterize it is obviously a subject requiring much further study, though perhaps by its nature 'the true value' can never be determined, since innovation is intrinsically not fully predictable. We remain to be convinced of the fully 'optimist' perspective that energy and related socioeconomic systems are ultimately completely adaptable: the drive for material consumption, the general wastefulness of human behavior, and the sheer ease of deriving energy from fossil fuels (especially oil and gas) suggests that abandoning them completely, more rapidly than dictated by resource exhaustion, would incur real long-run resource costs. But experience in analyzing energy technologies and systems internationally makes it plain that innovation and other forms of adaptive response are powerful factors, and that they are largely induced by the need to adapt to differing market and other conditions. The evidence from the various levels discussed above is overwhelming; and the response to the oil shocks and subsequent reversals, where as noted the response to price cuts in the 1980s appears to be only one-fifth of that for opposite and equal price rises in the 1970s, seems particularly striking. Our judgement, based on this varied evidence, is that reality lies somewhere between cases 2 and 3 considered above - between 'fully adaptive' and 'half and half'. 
Thus the various results outlined in this paper point to the central importance of gaining a better understanding of the issue of endogenous technological change and other adaptive responses, and the incorporation of these issues into integrated modeling frameworks. For example, Schlesinger (1993) argued on the basis of his modeling work that:

Rather than squabbling about near-term policies, the effects of whose differences are only minor, we should focus attention on the long-term major problem of providing energy worldwide.

This paper has demonstrated that if energy technologies and systems are indeed significantly adaptive, the logic in this quotation is perverse and self-defeating: it may be the act of abatement itself which starts to generate the possibility of long-term solutions to the energy/climate problem. In this case, delaying response would not only incur marginally higher costs of climatic impact from the interim emissions; it would delay the whole schedule of feasible abatement, and increase abatement costs, over the subsequent decades.

At present, a great deal of effort is going into understanding the dynamics of climate change, in terms of carbon cycles, ocean currents, sea level rise and the potential to adapt to climate change. The results here illustrate the central importance of paying equal attention to the dynamics of the potential solutions, as well as those of the problems, if effective and efficient responses to climate change are to be developed. In addressing environmental issues in the concluding part of The Prize, Yergin speculates that 'Perhaps, just perhaps, all this could point to a new direction for industrial society' - but to paraphrase the old Chinese proverb: unless we make some effort to change course, we are bound to end up where we are heading.

\section{References}

Anderson D, and Bird, C (1992) 'Carbon accumulations and technical progress - a simulation study of costs' Oxford Bulletin of Economics and Statistics 42 (1) (previously released as 1990, mimeo, University College, London)

Ausubel, J H (1991) 'Rat Race Dynamics and Crazy Companies: The Diffusion of Technologies and Social Behaviour' in Nakicenovic, $\mathrm{N}$ and Grübler, A (eds) Diffusion of technologies and social behaviour SpringerVerlag, Berlin/Heidelberg, p 10

Berndt, E, Kolstad, C and Lee, J K (1993) 'Measuring the energy efficiency and productivity impacts of embodied technical change The Energy Journal 14 (1)

Bovenberg, A L and Smulders, S (1994) Environmental Quality and Pollution-saving Technological Change in a Two-sector Endogenous Growth Model Fondazione Eni Enrico Mattei, Milan

Carraro, C, Lanza, A and Tudini, A (1994) Technological Change, Technology Transfer and the Negotiation of International Environmental Agreements International Environmental Affairs

Carraro, C and Siniscalco, D (1993) 'Policy co-ordination of sustainability: commitments, transfers and bandwagon effects' in Goldin 1 and Winters, L A (eds) Sustainable Development CEPR and Cambridge University Press

Chapuis, T, Ha-Duong, M and Grubb, M (1995) in preparation

Cline, W (1992) The Economics of Global Warming, Institute for International Economics Washington, DC

Edmonds, J, Pitcher, H, Rosenberg, N and Wigley, T (1993) 'Design for the global change assessment model' Paper presented at the International Workshop on Integrative Assessment of Mitigation, Impacts, and Adaptation to Climate Change, International Institute for Applied Systems Analysis, Laxenburg, 13-15 October

Freeman, C (1986) 'The diffusion of innovations microelectronic technology' in Roy, R and Wield, D (eds) Product Design and Technical Innovation Open University Press, extracted from 'Some economic 
implications of microelectronics' in Lundvall, B and Christensen, P R (eds) (1981) Technology and Emph yment Alborg University Press, Denmark

Gately. D (1993) "The imperfect price-reversibility of world oil demand" The Energy Journal 14 (4)

Grubb, M, Ha-Duong, M and Chapuis T (1994) 'Optimizing climate change abatement responses: on inertia and induced technology development' in Nakicenovic, N, Nordhaus, W D. Richels, R and Toth, F L (eds) Integrative Assessment of Mitigation, Impacts, and Adaptation to Climate Change CP-94-9. International Institute for Applied Systems Analysis, Laxenburg

Grubb, M (1993) 'Policy modelling for climate change: the missing models" Energy Policy 21 (3) 203-206

Grubb, M and Walker, J (1992) Emerging Energy Technologies: Impacts and Policy Implications RI1A/Dartmouth. Aldershot. UK/Brookfield VT

Grüibler, A, ( 1991 ) "Diffusion: long-term patterns and discontinuities' in Nakicenovic N and Grübler, A (eds) Diffusion of Technologies and Social Behavior Springer-Verlag, Berlin/Heidelberg

Hoeller, P, Dean. A and Hayafui, M (1992) A New Issues, New Results: The OECD's Second Survey 'the Macroeconomic Costs of Reducing CO2, Emissions OECD Working paper No 123, Paris

Hourcade, J.-C. (1993) 'Modelling long-run scenarios: methodology lessons from a prospective study on a low CO2 intensive country" Energy Policy 21 (3) 309-326

Johansson, T B et al (eds) (1993) Renewable Energy: Sources for Fuels and Electricity Island Press, Washington, DC

Nordhaus, W D (1991) 'To slow or not to slow: the economics of the greenhouse effect' The Economic Journal 101 (6) 920-937

Nordhaus, W D (1994) Managing the Global Commons: The Economics of the Greenhouse Effect MIT Press, Cambridge, MA

Schipper, L and Meyers, S (1993) Energy Efficienc'y and Human Activity', Cambridge University Press

Schlesinger, M E (1993) 'Greenhouse policy' Research and Exploration 9 (2)

Walker, 10 and Wirl, F (1993) 'Irreversible price-induced efficiency improvements: theory and empirical application to road transportation' The Energy, lournal 14 (4)

Watanabe. C, Santoso, I and Widayanti, T (1991) The Inducing Power of Japanese Technical Innovation Frances Pinter, London

World Energy Council (1992) Energy.for Tomorrow's World WEC, London 


\section{Appendix}

The model developed is a simplified optimizing benefit-cost model designed specifically for looking at the influence of adaptability and inertia upon optimal abatement responses, given an assumption that excess $\mathrm{CO}_{2}$ emissions lead to smoothly rising and quantifiable damages associated with rising $\mathrm{CO}_{2}$ concentrations (the model could by extension also be applied to other greenhouse gases with different lifetimes, but the focus here is upon the fossil $\mathrm{CO}_{2}$ element).

\section{Emissions and abatement costs}

Starting at the present time $t=0$, emissions $E(t)$ at time $t$ may deviate from a reference path $\operatorname{Er}(t)$ as determined by an abatement variable $e(t)$ :

$$
E(t)=\operatorname{Er}(t)[1-e(t)]
$$

where the reference $\operatorname{Er}(t)$ gives the $\mathrm{CO}_{2}$ emissions that would occur at time $t$ in the absence of any abatement effort.

Abatement $(e(t)>0)$ incurs a cost which, as outlined in the paper, is a quadratic function of both the degree and the rate of abatement:

$$
g a\left\{e(t), e^{\prime}(t)\right\}=C a e(t)^{2}+C b e^{\prime}(t)^{2}
$$

where $e^{\prime}(t)$ is the first derivative (ie the rate of change of abatement level), and $C a$ and $C b$ are constants which are set according the constraint on total abatement costs over a fixed period, as indicated in the text. This simple form for the cost function is in fact the heart of the new issues captured in the model. The first term is equivalent to the abatement cost function in existing aggregated cost-benefit studies such as Nordhaus's DICE model. The second is a direct reflection of inertia, in which costs depend on the rate of abatement. Emission trends in the absence of abatement efforts are uncertain, but as for population, nearly all studies project declining rates of exponential growth which can be well approximated bysimple linear projections ${ }^{15}$. The uncertainties in the actual rate of growth far outweigh any constraints imposed by this form. We therefore let

$$
E(t)=E(0)(1+\zeta t)
$$

where $\zeta$ is the average projected growth rate in emissions, in the absence of any abatement efforts, as a fraction of base year $(t=0)$ emissions.

\section{Atmospheric concentrations and impact costs}

The accumulation of $\mathrm{CO}_{2}$ in the atmosphere at time $\mathrm{t}$ (relative to pre-industrial levels), $M(t)$, is determined by the accumulation of emissions $E(t)$ less the rate of reabsorption by natural sinks:

$$
M^{\prime}(t)=E(t)-s M(t)
$$

where

15 Excluding those which (1) assume exponentially growing rates by construction (egrelating emissions directly to an exponentially growing GNP), or (2) build in assumptions that emissions will be drastically curtailed in the reference case. Emission trends in the last 40 years (1950-90) are surprisingly close to a linear trend. Projections of $\mathrm{CO}_{2}$ emissions by the World Energy Council (1992) in three different scenarios to the year 2020 all project linear increases. 
- $M(t)=$ the atmospheric accumulation of $\mathrm{CO}_{2}$ at time $t$ since preindustrial times

- $M^{\prime}(t)=$ the rate of change in atmospheric accumulation

- $E(t)=$ the $\mathrm{CO}_{2}$ emission rate at time $t$

- $s=$ a 'sink rate' removal constant

This equation assumes that carbon is removed from the atmosphere at a rate in direct proportion to the atmospheric accumulation. This is an adequate approximation for the present purposes; for longer term changes in particular it may be optimistic in that it does not recognize any saturation of the natural sinks. Given the simplification in the atmospheric model noted above (ie carbon removal proportionate to accumulation), the equation yields a direct expression for the concentration change (accumulation) remaining at date $t$ :

$$
M(t)=\exp (-s t) \times\left(M_{0}+\int_{[0, t]} E(u) \exp (-s u) \mathrm{d} u\right)
$$

The parameter $s$ may be evaluated from past data. Given a conservative estimate that only a third of total $\mathrm{CO}_{2}$ emissions accumulated in the atmosphere during the mid-1980s, $s$ is approximately $3.7 \% \mathrm{pa}^{16}$.

Then there is a cost associated with these atmospheric changes. The simplest possible form is chosen (since the focus of the model is upon the implications of changing the form of abatement costs), with the damage proportional to the atmospheric accumulation:

$$
g i\{M(t)\}=C i M(t)
$$

Since damages are widely expected to rise nonlinearly (eg exponentially) with global average temperature, but global average temperature is thought to be a roughly logarithmic function of $\mathrm{CO}_{2}$ concentration, this is not necessarily a biased approximation ${ }^{17}$. In reality of course we simply do not know the real form of damage function.

\section{Objective and optimality conditions}

The objective is taken as being to minimize the total discounted economic loss, where for simplicity the cost functions are expressed are scaled in proportion to gross world product:

$$
\operatorname{Min} \int_{[0, \infty]} \exp (-\rho t)\left(g a\left\{e(t), e^{\prime}(t)\right\}+g i\{M(t)\}\right) \mathrm{d} t
$$

where time $t$ is set such that $t=0$ represents the present, $\rho$ is the rate of utility time preference, and $g a$ and $g i$ are the cost functions for abatement and impacts as set out above. Applying the variational principle, in Grubb et al (1994) we show that an analytic solution for this set of equations can be derived to give the optimal abatement trajectory:

$$
e(t)=C b /(2 C a)[\zeta t+(1+\rho \zeta C b / C a)(1-\exp (-\Delta \rho t / 2))]
$$

with $\Delta=\operatorname{sqrt}\left(1+4 / \rho^{2} C a / C b\right)-1$

This equation describes the optimal degree of abatement $e(t)$ at time $t$, given the assumed quadratic dependence of abatement costs upon both $e(t)$ and $e^{\prime}(t)$, with the weight accorded to each determined by the constants $C a$ and $C b$. In Chapuis et al (1995) the model is developed in a more general form, and we also show how explicit equations can be derivedfor the cost of delay and other derivatives of this basic model.

$16 \mathrm{~s}=2 \mathrm{M}^{\prime} / \mathrm{M}=2 * 1.5 /(350-270)=0.37$ (carbon accumulation taken for convenience in $\mathrm{ppm}$ ).

17 If temperature change is taken as determined by a single-parameter heat lag system, this relationship is equivalent to assuming the impact costs depend on both the degree and rate of that temperature change, in a particular combination; see Grubb et al (1994). 


\section{Postscript [added in proof]}

Since this article was completed, two related important works have been drawn to the author's attention. Recent work by Hadi Dowlatabadi at CarnegieMellon University has examined the historical rate of technical change embodied in the 'Autonomous Energy Efficiency Indicator', a parameter that is almost universally applied as an exogenous variable in energy-climate modeling studies. His empirical analysis shows emphatically that the AEEI is not in reality autonomous; he suggests it should be replaced by an 'energy efficiency response model' of induced technical change that responds to energy prices with a response 'half life' of about 10 years. They estimate that in the period of declining energy prices from 1960 to 1975, this 'EERM' was about -1.6\%; in the period 1975 to 1990, following the energy price rises, it averaged $+1 \%$. This adds yet more, and more specific, empirical weight to the evidence set out in this paper.

Finally, Denis Anderson of the World Bank has drawn the author's attention to the relevance of a paper by the Nobel Laureate Kenneth Arrow more than 40 years ago: The economic implications of learning-by-doing (Review of Economic Studies, June 1962), Arrow observed that 'one empirical generalization is so clear that all schools of thought must accept it, although they interpret it in different fashions: learning is the product of experience ... I advance the hypothesis here that it is the very activity of production which gives rise ... to favourable responses over time'. He proceeds to develop a general model incorporating such learning-by-doing, noting the basic result that 'the presence of learning means that an act of investment benefits future investors, but this benefit is not paid for by the market the aggregate amount of investment [in the normal competitive market] will fall short of the socially optimum level'.

In that sense, induced technical change can be considered as an external benefit, one which in the context of climate change is additional Io the direct benefits of reduced emissions. Since climate change is such a very long term phenomena, it is only to be expected that induced technical change should have a large role to play. The only surprise is that almost all the economic modeling literature on climate change to date has ignored the issue like the plague. The only contribution of this paper is to highlight its importance, with a novel analytic approach and results that suggest that these indirect benefits may magnify by many times the direct environmental benefits derived from emission controls. 


\section{Figures}
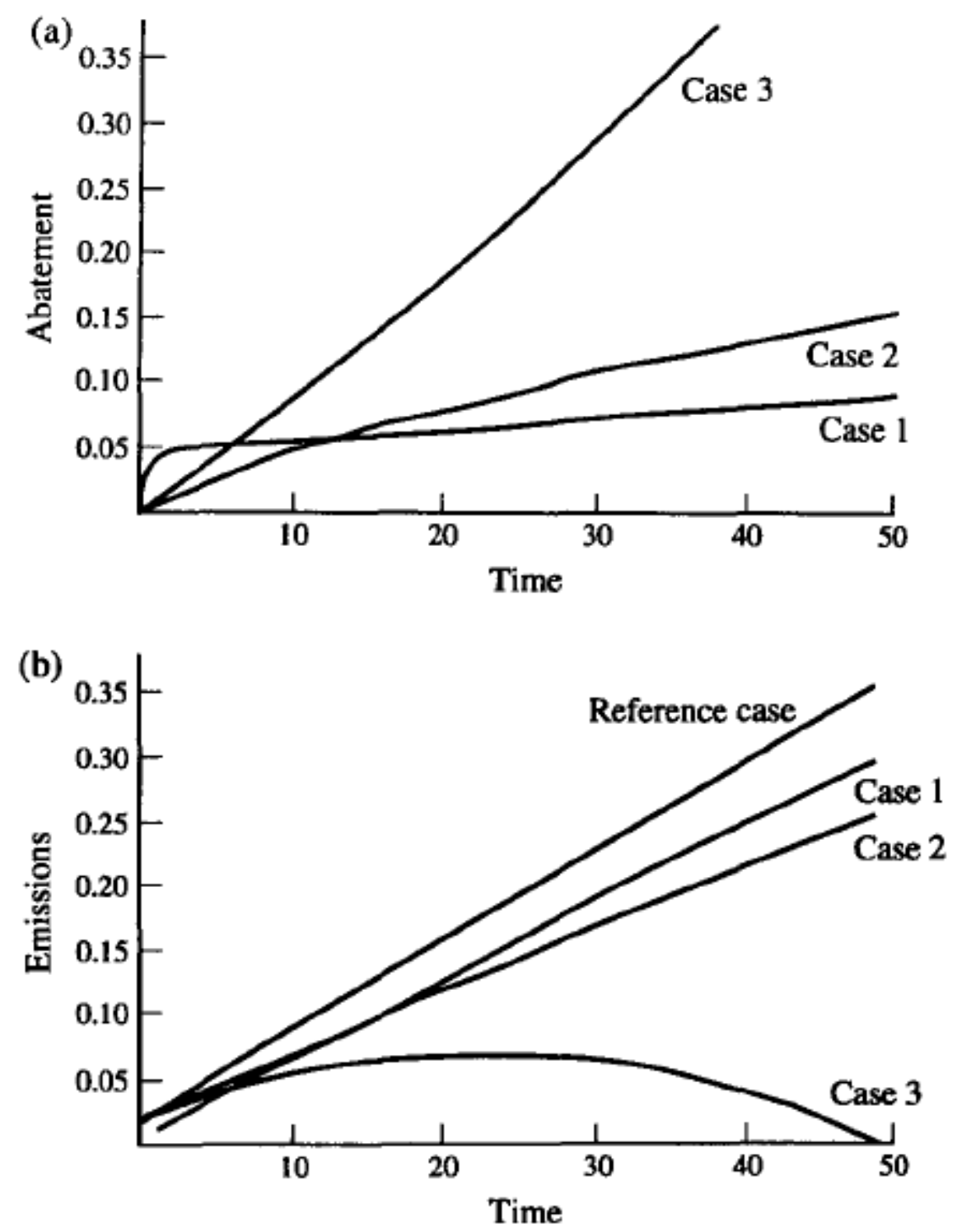

Figure 1: The impact of adaptation and inertia on optimal abatement responses (3\% RTP). The figure shows optimal responses given assumptions summarized in the text, for each of three test cases: (1) non-adaptive, low inertia; (2) half and half; (3) adaptive, high inertia. The case with $3 \%$ rate of time preference is shown. 

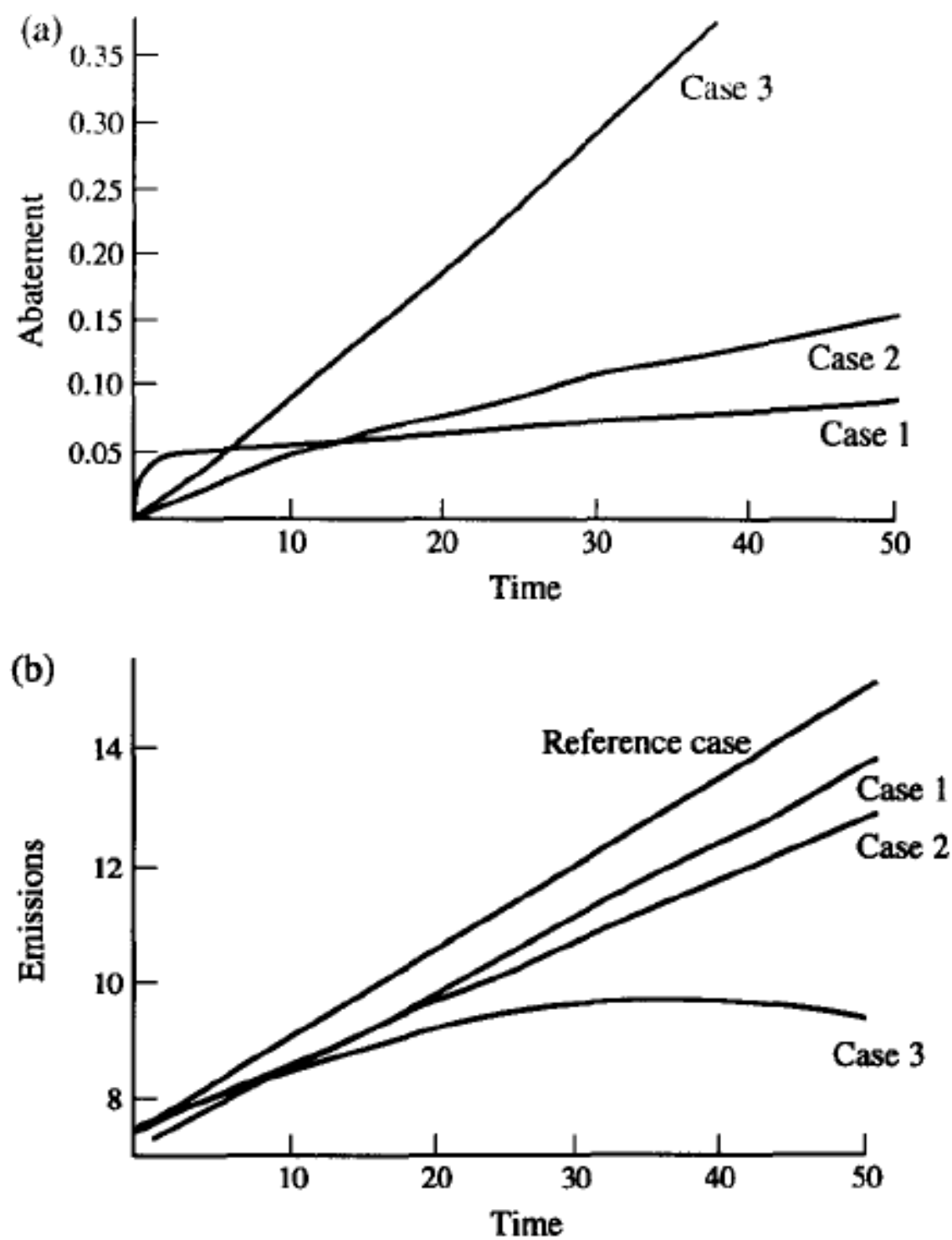

Figure 2: The impact of adaptation and inertia on optimal abatement responses (4\% RTP) The figure shows optimal responses given a $4 \%$ rate of time preference and other assumptions summarized in the text, for each of three test cases: (1) non-adaptive, low inertia; (2) half and half; (3) adaptive, high inertia. 

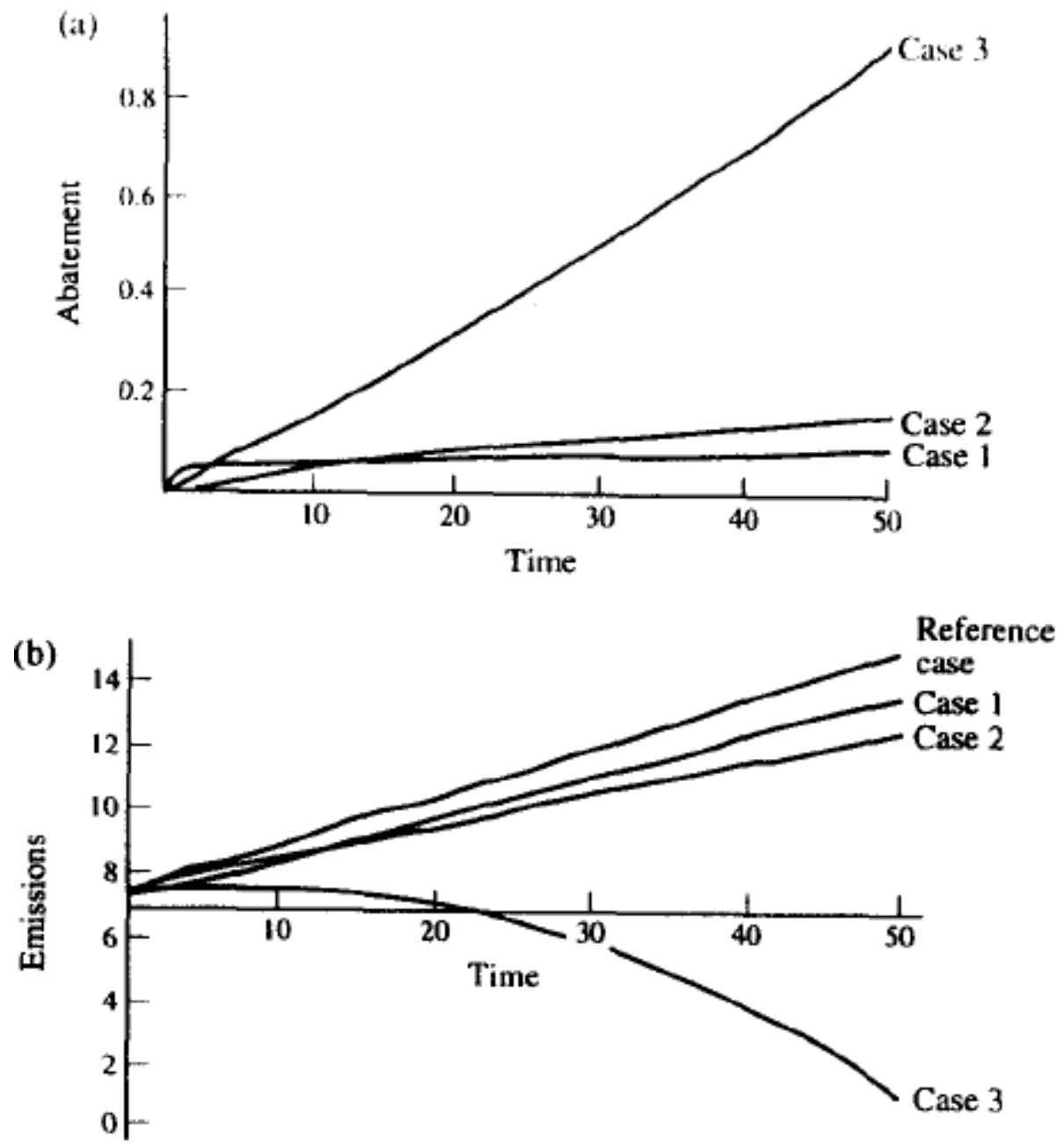

Figure 3: The impact of adaptation and inertia on optimal abatement responses (2\% RTP) The figure shows optimal responses given a $2 \%$ rate of time preference and other assumptions summarized in the text, for each of three test cases: (1) non-adaptive, low inertia; (2) half and half; (3) adaptive, high inertia. 

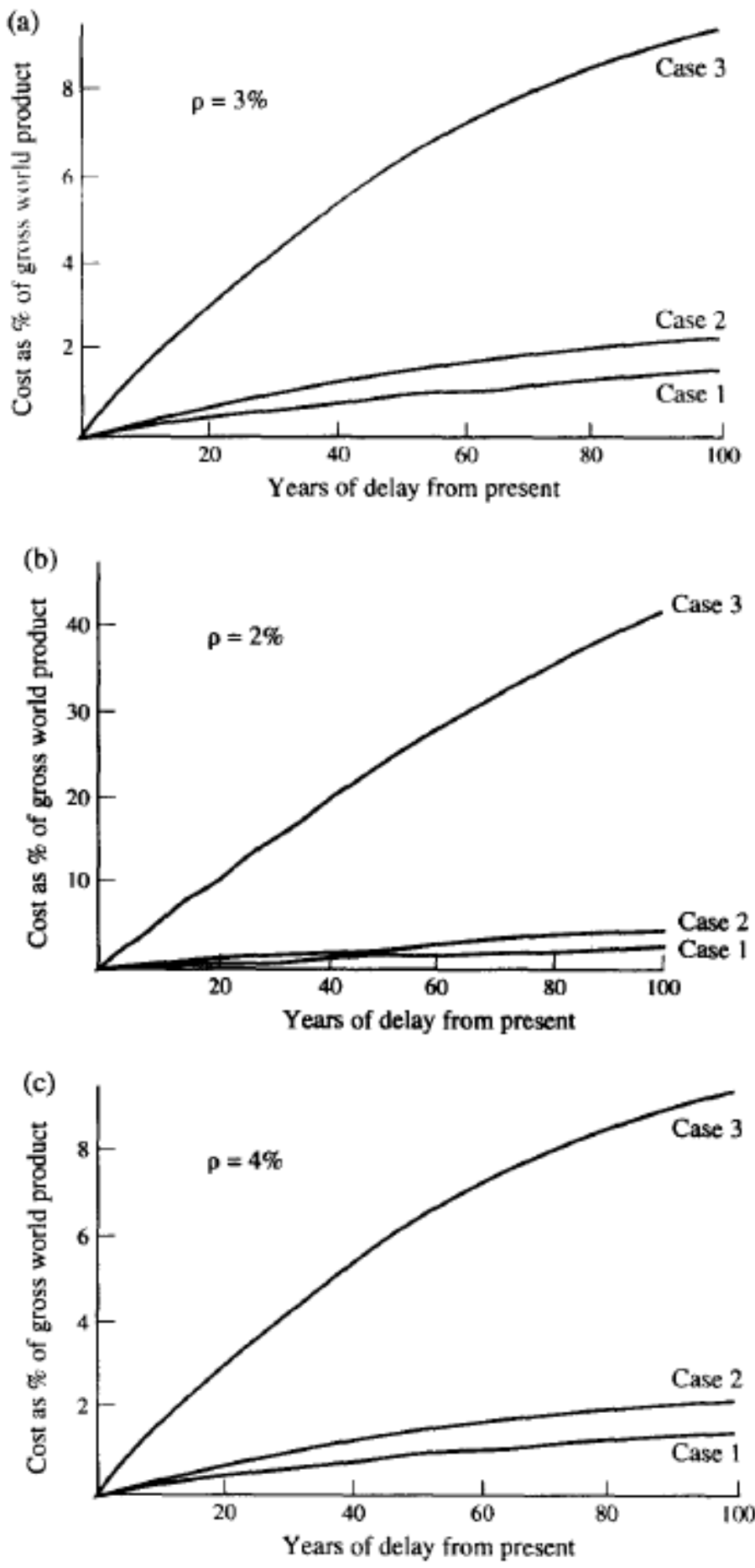

Figure 4: The cost of delay The figure shows the cumulative cost (as pecentage of gross world product, discounted to the current year) of delaying any abatement response by a given duration for each of the three test cases: (1) non-adaptive, low inertia; (2) half and half; (3) adaptive, high inertia. After the delay, an optimal response is made from the position then reached, assuming $3 \%$ rate of time preference and other assumptions summarized in the text. 